\title{
Socio-cultural Aspects of Informatization in the Context of the Effective General (Secondary) Education Formation
}

\section{Denis Vadymovich Zherdev¹, Vladimir Lazarevich Nazarov²,3, and Natalya Vladimirovna Averbukh ${ }^{4}$}

${ }^{1}$ Department of Philology Education Of The Specialized Scientific Center of the Ural Federal University named after the first President of Russia B. N. Yeltsin, Yekaterinburg, Russian Federation

${ }^{2}$ Department of Youth Organization of the Ural Federal University named after the first President of Russia B. N. Yeltsin, Yekaterinburg, Russian Federation

${ }^{3}$ Department of Project Management in Education of the Institute for Education Development of the Sverdlovsk Region, Yekaterinburg, Russian Federation

${ }^{4}$ Laboratory of brain and neurocognitive development of the Urals Humanitarian institutional, Ural Federal University named after the first President of Russia B. N. Yeltsin, Yekaterinburg, Russian Federation

Corresponding Author: Denis Vadymovich Zherdev Denis.Zherdev@urfu.ru

Published: 21 January 2021

Publishing services provided by Knowledge E

(c) Denis Vadymovich Zherdev et al. This article is distributed under the terms of the Commons Attribution License, which permits unrestricted use and redistribution provided that the original author and source are credited.

Selection and Peer-review under the responsibility of the XXIII International Conference Conference Committee.

\section{Abstract}

This article is devoted to the preparation of an information base for the formation of criteria for assessing the process of general (secondary) education informatization. The situation in education can be considered as unstable, lacking a clear understanding of the social, psychological and technological prospects for the Russian and world communities' development, which excludes the possibility of correct strategic planning and making correct management decisions. The development source of uncertainty is the very transitional nature of the current situation in ICT - equally in the technological, economic, sociocultural and psychological aspects. The research problematizes the well-established idea of the modern relations of education and ICT, emphasize the lack of empirical data and the bias towards a normative approach in the field of managerial decisions, which in the face of uncertainty leads to the adoption of erroneous decisions (a tactics and strategy contradiction). The research has determined the prospects for a monitoring research system designed to obtain the necessary empirical data in the system, taking into account the change in the technological and sociocultural paradigm over the past decade.

Keywords: information society, digitalization of education, efficiency in education, digital divide, resistance to innovation

\section{Introduction}

The problem of a digital educational environment formation adequate to the modern state of the info-sphere and the most comfortable conditions creation for the all ages students' creative development is discussed in the scientific field. However, except for pilot methodical and historical studies of the period of 80-90 years of the last century [9], 
we can talk about the systematic lag of fundamental research from the rapidly changing information and socio-cultural situation. Society's transformation requires using fundamentally new tools in the education system, such as Big Data analysis and artificial intelligence. This need seems to be realized in the Russian Federation both at the level of education management (from federal ministries to organizations of secondary (general) education in the field), and at the level of direct participants in the educational process. Nevertheless, neither a real understanding of informatization goals and prospects, nor a qualitative tracking of its results, no an analyses of expected and real social consequences at the moment have not been carried out. In fact, the educational community is in a state of empirical search and adaptation in conditions of a modern society transformation [6]. In this situation, the priority task is to carry out a set of monitoring studies, the results of which should become the basis for the construction of a fundamental model of the general education system digital transformation.

\section{Methodology and Methods}

The study is carried out in several main stages. At the preparatory stage, the focus group method is used to initially identify the spectrum of participants' perception referring to the educational process levels. Three main categories of participants were identified: students, their parents and teachers. Three focus groups with each category representatives'were carried out. In the second stage, based on the analysis of focus group data, the main directions of surveys were formulated. The third stage included the testes results referring to the basis of pilot project (SUNC UrFU, MAOU "Gymnasium No. 35" in Yekaterinburg, etc.).

\section{Results and Discussion}

The education informatization and the large-scale introduction of digital technologies has entered many state programs, is deployed in the GEF of general (secondary) education [4]. The study of the education digital transformation demonstrates the extreme ambiguity of the results [5], etc. The scope of the information competence curriculum acquired by students includes, as a rule, primitive possession of office and presentation programs and limited skills in the use of free graphics applications. The area of management uses opaque data systems that are unsuitable for external audit and data analysis even at the regional level since education as a whole is not a priority for software manufacturers. This usually means either a very limited capability of the final 
product made by non-professionals or provided under a limited educational license or a lack of development and extreme non-ergonomics of the client component of the product, as a result of which the introduction of ICT does not simplify, but significantly complicates the educational process, as well as related knowledge-intensive areas of activity: "IN a number of cases, computerization of management processes due to unsuccessful implementation of software and hardware complexes, as well as general problems with the organization, leads to difficulties in the work of institutions. Instead of the expected acceleration and ease of work, additional workload on office workers creates, which leads to errors, and as a result, to stresses, employees and visitors (customers). Again, long lines and complaints about the bureaucracy of officials appear, etc." [2]. In the field of work with information networks, educational authorities prefer to adhere to a prohibitive policy - the method is generally called dysfunctional (in theory) and, in practice, virtually non-alternative, since preparation for critical selection and comprehension of information, which, in principle, can serve as an alternative to direct prohibitions, in the vast majority of cases remains at the level of declarations, moreover, its results are not recognized as adequate social demands by all the participants of the educational process.

Thus, in the end, it is a very limited understanding of digitalization, which, with the classic description of S. Parkinson: "For one million pounds sterling, a new computer is bought - a symbol of progress". Of course, the requirements of GEF and EGE for a profile-level computer science course imply a sufficiently serious study of the basics of programming. However, this happens against the background of a stormy discussion in the profile media about the upcoming "death of encoding" [1], [3], [8]. In general, it seems that, neither the educational authorities at the federal and local level, nor the researchers monitoring the results of the digital transformation of Russian society, have any conscious and motivated criteria for assessing the situation and are forced to rely on purely external indicators. For example, the study of HSE specialists [10] related to the understanding and use of high-level ICT by scientists of the Russian Federation. The results presented in the study look almost catastrophic against the background of declared priorities of state policy in this sphere. The problem, however, is that the study itself does not consider how much the use (and knowledge) of the technologies mentioned in it is generally understood and demanded for the surveyed categories of researchers.

Indeed, ICT is simultaneously perceived as a fundamental threat to the humanity's existence. Sometimes it is considered as a source of order and a source of chaos, as a new good and a new Evil - and often in the same declarations or different speeches of 
the same subjects there is an appeal to formally incompatible epistemological models of the digital world perception [6]. It is quite expected, since the info sphere at the point of bifurcation really gives grounds for almost any, however positive or negative assessment. As a result, the issues of determining the strategy of the education development in the Russian Federation is inevitably based on the unresolved problems of the level of self-determination and the realized prospects for the development of modern civilization.

Although focus groups have not provided objective data, they allow us outlining the circle of the educational process participants' mutual interests- trainees, teacherseducational and parents as one of the education service key "'customers'. Focus groups should be conducted separately with these groups, as they distinguish between basic needs and a level of adaptation to the digital world [9].

It leads to the inevitable replacement of value landmarks, and further to a change in the structure of the personality, determining ways of cognitive activity in particular.

As for older people, especially educators, additional attention will be paid to the problem of their resistance to innovation and rejection of digital transformations based on fears of social, cultural, ideological plans and etc. It should be noted that such concerns are often based on real problems related to current social and/or administrative practices (when the transfer to the electronic document management system is an additional burden on teachers, and the installation of digital educational resources is adjacent to the setting for reducing the paid load), on real counter-cultural excesses, such as criminal, terrorist, or suicidal communities on the Internet and etc. To investigate the situation in this sphere, an anonymous open-type survey using both paper and Internet forms is launched.

The study has allowed us to developing a system of criteria for assessing the situation in education that is enough to reach the level of strategic planning.

\section{Conclusions}

The modernization of education in accordance with the requirements of the information society requires, firstly, the communication system reorganization. Traditional (linear) education is based on frontal translation and book-writing form of communication and fixing the result.

The realities of the information society require a shift to the use of universal digital skills, including free search and critical evaluation of information in the lack of an authoritative source, as well as the fixation of results directly in the info sphere in the 
mode of free exchange of multi-format data and the joint generation of digital content and publicity.

The study has shown that a partial transition to new educational forms is, on the one hand, a result of the national programs for the digitization of the economy and education implementation, and, on the other hand, a result of students' general involvement in the modern information and communication environment. As a result of insufficient situation reflection, educational authorities at both the municipal and federal levels set adequate tasks only in the field of training programs and state attestation activities. At the strategic level, the education transition to new forms remains a system of declarations.

In Order to radically change the situation, a toolkit for collecting and adequately assessing the state of ICT education is needed, suitable for real-time work. It should include using artificial intelligence technologies to analyze the situation referring to implicit factors such as the student's 'digital trace' in the educational process in a situation of "continuous education".

\section{Acknowledgments}

The reported study was funded by RFBR, project number 19-29-14176 MK

\section{References}

[1] Auerbach, D. Software Engineers will be Obsolete by 2060. (2015, August). Retrieved February 20, 2020 from https://medium.com/@dtauerbach/software-engineers-willbe-obsolete-by-2060-2a214fdf9737\#.mvivzgsb8.

[2] Averbukh, V. L. and Averbukh, N. V. (2015). Ergonomics of Mass and Professional Interfaces. Ergonomist. Bulletin of the Interregional ergonomic Association, issue 39, pp. 5-14.

[3] Church, M. O. What Will a Programmer Job be Like in 20-30 Years? (2015, April). Retrieved February 20, 2020 from https://www.quora.com/What-will-a-programmerjob-be-like-in-20-30-years/answer/Michael-O-Church.

[4] Federal State Educational Standard of Secondary General Education (ed. Orders of the Ministry of Education of Russia from 29.12.2014 N 1645, from 31.12.2015 N 1578, from 29.06.2017 N 613) Retrieved February 20, 2020 from http://classinform.ru/fgos/ 1.4-srednee-obshchee-obrazovanie-10-11-class.html.

[5] Nazarov, V. L (2018). "BIG GAME" V. 2.0: Russia in the Global Information Space: Monograph. Ekaterinburg: Ural University Publishing House, p. 304. 
[6] Nazarov, V. L. and Zherdev, D. V. (2018). Information Aggregation in context of Epistemological models of Info sphere. Presented at Proceedings of the International Conference Communicative strategies of Information Society (CSIS 2018, SaintPetersburg, Russia).

[7] Nazarov, V. L. (2017, December). Modern Technologies of Intellectual Analysis of Internet Users. In Innovative Potential of Youth. Information, Social and Economic Security: Collection of Articles of Participants International Youth Scientific-Research Conference. Yekaterinburg: UrFU, pp. 146-150.

[8] ORNL. (2018, September). Retrieved February 20, 2020 from https://ornl.gov/news/ ornl-developed-technology-streamlines-computational-science-projects.

[9] Gtmarket.ru. (2011, January). Retrieved February 20, 2020 from http://gtmarket.ru/ laboratory/basis/4821.

[10] Issek.hse.ru. (2018, March). Retrieved February 20, 2020 from https://issek.hse.ru/ news/216441485.html. 